\title{
Synthesis, structure refinement and chromate sorption characteristics of an Al-rich bayerite-based layered double hydroxide
}

\author{
Sylvia Britto*, P. Vishnu Kamath \\ Department of Chemistry, Central College, Bangalore University, Bangalore 560001, India
}

\section{A R T I C L E I N F O}

\section{Article history:}

Received 21 August 2013

Received in revised form

10 February 2014

Accepted 21 February 2014

Available online 21 March 2014

Keywords:

Intercalation

Rietveld refinement

Layered hydroxides

\begin{abstract}
A B S T R A C T
"Imbibition" of $\mathrm{Zn}^{2+}$ ions into the cation vacancies of bayerite- $\mathrm{Al}(\mathrm{OH})_{3}$ and $\mathrm{NO}_{3}^{-}$ions into the interlayer gallery yields an $\mathrm{Al}$-rich layered double hydroxide with $\mathrm{Al} / \mathrm{Zn}$ ratio $\sim 3 . \mathrm{NO}_{3}^{-}$ions are intercalated with their molecular planes inclined at an angle to the plane of the metal hydroxide slab and bonded to it by hydrogen bonds. Rietveld refinement of the structure shows that the monoclinic symmetry of the precursor bayerite is preserved in the product, showing that the imbibition is topochemical in nature. The nitrate ion is labile and is quantitatively replaced by $\mathrm{CrO}_{4}^{2-}$ ions from solution. The uptake of $\mathrm{CrO}_{4}^{2-}$ ions follows a Langmuir adsorption isotherm, thus showing that the hydroxide is a candidate material for green chemistry applications for the removal of $\mathrm{CrO}_{4}^{2-}$ ions from waste water. Rietveld refinement of the structure of the hydroxide after $\mathrm{CrO}_{4}^{2-}$ inclusion reveals that the $\mathrm{CrO}_{4}^{2-}$ ion is intercalated with one of its 2 -fold axes parallel to the $b$-crystallographic axis of the crystal, also the principal 2 axis of the monoclinic cell.
\end{abstract}

(c) 2014 Elsevier Inc. All rights reserved.

\section{Introduction}

$\mathrm{Al}(\mathrm{OH})_{3}$ is a layered hydroxide and comprises charge-neutral layers having the composition $\left[\mathrm{Al}_{2 / 3} \square_{1 / 3}(\mathrm{OH})_{2}\right]$ ( $\square=$ cation vacancy). The packing of hydroxyl ions is similar to that in mineral brucite, $\mathrm{Mg}(\mathrm{OH})_{2}$. The cation vacancies within the metal hydroxide sheets are ordered yielding an ' $a$ ' parameter $=\sqrt{ } 3 \times \times a_{\text {o }}$ wherein $a_{o}$ corresponds to the ' $a$ ' parameter in $\mathrm{Mg}(\mathrm{OH})_{2}$.

The intralayer bonding is strong ionocovalent and interlayer bonding is weak van der Waal's. As a consequence of the anisotropy in bonding, the layers can be stacked one above the other in different ways giving rise to a range of polytypes known as bayerite [1], gibbsite [2], nordstrandite [3] and doyleite [4]. The vacancies in the $\left[\mathrm{Al}_{2} \square(\mathrm{OH})_{6}\right]$ layer can be filled with $\mathrm{Li}^{+}$ions to yield positively charged layers of the composition $\left[\mathrm{Al}_{2} \mathrm{Li}(\mathrm{OH})_{6}\right]^{+}$. Simultaneous incorporation of anions in the interlayer region restores charge neutrality, yielding a layered double hydroxide ( $\mathrm{LDH})$ of the composition $\left[\mathrm{LiAl}_{2}(\mathrm{OH})_{6}\right]\left[\mathrm{A}^{n-}\right]_{1 / n} \cdot y \mathrm{H}_{2} \mathrm{O}(\mathrm{A}=$ anion $)$ [5]. Given the diversity of polytypes in the precursor $\mathrm{Al}(\mathrm{OH})_{3}$, the $\mathrm{Li}-\mathrm{Al}$ LDHs also crystallize in diverse structures. LDHs obtained from gibbsite crystallize in structures of hexagonal symmetry [6], while those obtained from bayerite, crystallize in structures of monoclinic symmetry [7].

\footnotetext{
* Corresponding author.

E-mail address: sylviabritto11@gmail.com (S. Britto).
}

Another way of imparting a positive charge to the $\left[\mathrm{Al}_{2} \square(\mathrm{OH})_{6}\right]$ layers is to insert divalent cations $\mathrm{M}^{2+}\left(\mathrm{M}=\mathrm{Ni}^{2+}, \mathrm{Zn}^{2+}, \mathrm{Co}^{2+}\right)$ in half the number of available vacancies to generate layers with the composition $\left[\mathrm{M}_{0.5} \mathrm{Al}_{2} \square_{0.5}(\mathrm{OH})_{6}\right]^{+}$[8]. Incorporation of anions in the interlayer region leads to layered double hydroxides having the composition $\left[\mathrm{MAl}_{4} \square(\mathrm{OH})_{12}\right]\left[\mathrm{A}^{n-}\right]_{2 / n} \cdot x \mathrm{H}_{2} \mathrm{O}$ (A=anion). For brevity, we refer to this formula with the symbol [M-Al4-A].

Fogg et al. [9] first synthesized the [M-Al4-nitrate] $(M=\mathrm{Zn}$, $\mathrm{Ni}, \mathrm{Co}$ ) LDHs using activated gibbsite as a precursor. This novel compound had an interlayer spacing of 8.5 A. Structure refinement of the as-prepared $\mathrm{LDH}$ was not attempted on account of the disorder in the intercalated nitrate ions and water molecules. Removal of intercalated water was found to introduce ordering of the nitrate ions in the interlayer. The $\mathrm{LDH}$ was dehydrated $\left(175^{\circ} \mathrm{C}\right.$, $6 \mathrm{~h}$ ) to facilitate structure refinement. The results of preliminary structure refinement of the dehydrated LDH were provided although the powder pattern of the dehydrated LDH itself was not presented. Their work suggested the formation of metal hydroxide layers as indicated by the idealized formula. The $\mathrm{Zn}^{2+}$ ions and vacancies were reported to be arranged alternatively along the c-crystallographic axis. Subsequently we synthesized the [Zn-Al4-sulfate] LDH starting from bayerite [10] and showed that the compound crystallized in the structure of the mineral nickelalumite [11]. In a recent paper [12], O'Hare's group have completed the refinement of the [M-Al4-nitrate] structure whose preliminary results they had reported earlier [9]. In their later paper they present the PXRD pattern of the dehydrated LDH which reveals an interlayer spacing of $8.32 \AA$, showing that dehydration 
does not result in any significant contraction of the interlayer spacing.

The reported structure has a few outstanding issues which have not been adequately addressed. (i) A plot of the structure using the reported atomic coordinates appears to contain face sharing as well as corner sharing octahedra which are chemically not expected. (ii) Prolonged heating at $175^{\circ} \mathrm{C}$ could induce the migration of $\mathrm{Zn}^{2+}$ ions from octahedral to tetrahedral sites which vitiates the choice of the structure model. (iii) There appear systematic residual intensities in the difference profile after the final stage of the refinement, that indicates that not all the electron density is accounted for. (iv) The detailed interlayer structure namely, the mode of coordination and nature of ordering of the nitrate ions is also not fully described.

While the domain of possible polytypes that may result from a layer of a particular symmetry may be arrived at by the structural synthon approach [13], polytype selection under a given set of experimental conditions is governed by a number of other factors which include the molecular symmetry of the intercalated anion, its mode of coordination and its capacity to make hydrogen bonds with the metal hydroxide layer. It is therefore important to gain an understanding of the packing of atoms in the interlayer gallery. In this paper we refine the structure of the as-prepared [Zn-Al4-nitrate] LDH including that of the interlayer. We also exchange the nitrate ion for chromate ions from solution, refine the structure of the [Zn-Al4-chromate] LDH and carry out sorption studies.

\section{Experimental}

[Zn-Al4-nitrate] LDH was prepared by soaking $0.5 \mathrm{~g}$ of bayerite in $\sim 6.5 \mathrm{M}(40 \mathrm{~mL}) \mathrm{Zn}\left(\mathrm{NO}_{3}\right)_{2}$ solution and hydrothermally treating the suspension in a Teflon lined autoclave ( $50 \%$ filling) at $150{ }^{\circ} \mathrm{C}$ for $24 \mathrm{~h}$. The products were washed 4-5 times with distilled water, once with isopropanol and then dried in an air oven at $65{ }^{\circ} \mathrm{C}$.

Anion exchange of the intercalated nitrate for chromate ions from solution was carried out by suspending $0.2 \mathrm{~g}$ batches of the LDH in $30 \mathrm{~mL}$ of a solution containing 10 times the stoichiometric requirement of chromate, taken in the form of the $\mathrm{K}_{2} \mathrm{CrO}_{4}$. The reaction was carried out for $24 \mathrm{~h}$ with stirring after which the solid was separated by centrifugation and washed with deionized water.

\subsection{Chromate uptake studies}

Pre-weighed $(0.20 \mathrm{~g})$ batches of the LDH were suspended in $25 \mathrm{~mL}$ of $1 \mathrm{M} \mathrm{KNO}_{3}$ solution made up to $0.008-0.1 \mathrm{M}$ (pH 8.5-9.0) in chromate ions taken in the form of $\mathrm{K}_{2} \mathrm{CrO}_{4}$. In this way, the ionic strength of the solution was kept nearly constant to maintain equilibrium conditions required for Langmuir adsorption. The slurry was stirred for $24 \mathrm{~h}$ at the ambient temperature $\left(24-26^{\circ} \mathrm{C}\right)$ after which it was centrifuged and the chromate concentration of the centrifugate was determined by means of potentiometric titration versus standard $(0.025-0.1 \mathrm{~N})$ ferrous ammonium sulfate (FAS) solution. For lower chromate concentrations ( $\leq 0.025 \mathrm{M}$ ), a larger volume (50-500 mL) of the $\mathrm{K}_{2} \mathrm{CrO}_{4}$ solution was used to affect the chromate uptake. The chromate uptake by the LDH was calculated from the difference in the initial and final chromate concentrations and is reported in moles of chromate uptake per gram of LDH taken. The isotherm was used to obtain a Langmuir plot.

\subsection{Characterization}

All samples were characterized by powder X-ray diffraction (Bruker D8 Advance Diffractometer, Cu K $\alpha$ radiation, $\lambda=1.5418 \AA$, reflection geometry). Data were collected at a continuous scan rate of $1^{\circ} 2 \theta \min ^{-1}$ and a step size of $0.02^{\circ} 2 \theta$. For Rietveld refinement, data were collected over $5-100^{\circ} 2 \theta$ (step size $0.02^{\circ} 2 \theta$, 10 s step $^{-1}$ ).

Rietveld refinement was carried out using the GSAS software package [14] using the structure of nickelalumite as the model to describe the metal hydroxide layer. The atomic coordinates of interlayer atoms were found using the program FOX [15]. For refinement, a TCH-pseudo-Voigt line shape function (Profile Function 2) with eight variables was used to fit the experimental profile. A cosine Fourier series function with eight terms was used to refine the background. Bond distance restraints were imposed on $\mathrm{Al}-\mathrm{O}(1.940 \pm \pm 0.05 \AA)$ and $\mathrm{Zn}-\mathrm{O}(2.050 \pm \pm 0.05 \AA)$ bonds to enable stable refinement. The relative weights of these restraints were reduced as the refinement progressed.

IR spectra were recorded using a Bruker Alpha-P FTIR spectrometer (ATR mode, $400-4000 \mathrm{~cm}^{-1}, 4 \mathrm{~cm}^{-1}$ resolution). The LDH composition was determined by a combination of chemical and instrumental methods. $\mathrm{Al}^{3+}$ content was estimated gravimetrically as $\mathrm{Al}_{2} \mathrm{O}_{3}$. The divalent metal ion content was estimated by Atomic Absorption Spectroscopy (Varian Model AA240 atomic absorption spectrometer). The nitrate content of the LDH was determined by ion chromatography (Metrohm Model 861 Advanced Compact Ion Chromatograph fitted with a Metrosep A SUPP5 anion column and conductivity detector). The chromatograph was calibrated using standard solutions prepared from AR grade $\mathrm{NaNO}_{3} / \mathrm{K}_{2} \mathrm{CrO}_{4}$ reagents (Aldrich Chemical Co., USA). The layer charge estimated on the basis of the $[\mathrm{Al}] /[\mathrm{Zn}]$ ratio is found to match with the nitrate content estimated by ion chromatography. The unaccounted mass after accounting for the metal, nitrate and hydroxyl contents is attributed to intercalated water (see Table 1). The total mass loss expected for this composition is verified by thermogravimetry analysis (Metler Toledo TG/SDTA Model $851^{\mathrm{e}}$ system, $30-800{ }^{\circ} \mathrm{C}$, heating rate $5^{\circ} \mathrm{min}^{-1}$, flowing air).

Diffused reflectance UV-vis absorption spectra were obtained using a Shimadzu ISR-3100 UV-vis-NIR scanning spectrophotometer. The spectra were recorded from $200-800 \mathrm{~nm}$.

\section{Results and discussion}

\subsection{Structure of the [Zn-Al4-nitrate]LDH}

Layered hydroxides, on account of anisotropy in bonding, often exhibit poor crystallinity and crystallize with varying proportions of stacking faults, which lead to extensive broadening of the reflections in the PXRD patterns of these materials. Single crystals of these materials are rare and obtainable only from mineral sources. Laboratory synthesized materials crystallize as polycrystalline powders. Refinement of the structures of the layered double hydroxides therefore poses a considerable challenge. The PXRD pattern of [Zn-Al4-nitrate] (Supporting information, SI. 1 and 2), however, exhibits sharp reflections and can be indexed on the basis of a monoclinic cell belonging to the $P 12_{1} / n 1$ space group $\left(a=10.2917(3) \AA, b=8.9211(6) \AA, c=17.1612(6) \AA, \beta=95.2^{\circ}\right)$.

A successful structure refinement is contingent upon the selection of a suitable structure model. An LDH comprises two

Table 1

Results of wet chemical analysis and TGA data.

\begin{tabular}{|c|c|c|c|c|}
\hline Sample & $\begin{array}{l}\mathrm{Al} / \mathrm{Zn} \\
\text { ratio }\end{array}$ & $\begin{array}{l}\mathrm{A}^{n-} / \mathrm{Zn} \\
\text { ratio }\end{array}$ & $\begin{array}{l}\% \text { mass loss } \\
\text { from TGA }\end{array}$ & $\begin{array}{l}\text { Approx. composition } \\
\text { of sample }\end{array}$ \\
\hline $\mathrm{Zn}-\mathrm{Al}-\mathrm{NO}_{3} \mathrm{LDH}$ & 2.96 & 1.2 & 48.3 & $\begin{array}{l}{\left[\mathrm{Zn}_{0.207} \mathrm{Al}_{0.0612}(\mathrm{OH})_{2}\right]} \\
{\left[\mathrm{NO}_{3}\right]_{0.25} \cdot 0.74 \mathrm{H}_{2} \mathrm{O}}\end{array}$ \\
\hline $\mathrm{Zn}-\mathrm{Al}-\mathrm{CrO}_{4} \mathrm{LDH}$ & 2.96 & 0.59 & 43.7 & $\begin{array}{l}{\left[\mathrm{Zn}_{0.207} \mathrm{Al}_{0.0612}(\mathrm{OH})_{2}\right]} \\
{\left[\mathrm{CrO}_{4}\right]_{0.122} \cdot 1.29 \mathrm{H}_{2} \mathrm{O}}\end{array}$ \\
\hline
\end{tabular}


structure modules: (i) the metal hydroxide layer and (ii) the interlayer comprising a sheet of hydrated anions.

One of the minerals having the model [M-Al4] composition in the metal hydroxide layer is nickelalumite. In this $\mathrm{Ni}^{2+}$ ions are inserted into half the cation vacancies of the $\mathrm{Al}(\mathrm{OH})_{3}$ layer to yield the nominal empirical formula $\left[\mathrm{Ni}_{0.5} \square_{0.5} \mathrm{Al}_{2}(\mathrm{OH})_{6}\right]\left[\mathrm{SO}_{4}\right]_{0.5} \cdot y \mathrm{H}_{2} \mathrm{O}$, with the idealized $[\mathrm{Al}] /[\mathrm{M}]$ ratio 4 . However, our preparation (Table 1 ) has a lower $[\mathrm{Al}] /[\mathrm{M}]$ ratio of 2.96 , corresponding to a layer composition $\left[\mathrm{Zn}_{0.621} \mathrm{Al}_{1.836}(\mathrm{OH})_{6}\right]$. This suggests that some of the excess $\mathrm{Zn}^{2+}$ substitutes for $\mathrm{Al}^{3+}$ in the layer $\left[\left(\mathrm{Zn}_{0.5} \square_{0.5}\right)\right.$ $\left.\left(\mathrm{Al}_{1.836} \mathrm{Zn}_{0.121} \square_{0.043}\right)(\mathrm{OH})_{6}\right]^{0.75+}$. The structure of the metal hydroxide layer was modeled in this manner using the atomic position coordinates extracted from the published structure of nickelalumite [11] (space group $P 2_{1} / n$, cell parameters: $a=10.305(3) \AA$, $b=8.911$ (2) $\AA, c=17.141$ (2) $\left.\AA, \beta=95.68(2)^{\circ}\right)$. This provided the partial structure model for the refinement.

Modeling the interlayer was more difficult. Nickelalumite comprises sulfate ions in the interlayer. In a nitrate-LDH, the exigency of charge compensation requires that twice the number of nitrate ions as the number of sulfates in the model structure, be accommodated in the interlayer gallery. Thereby the crystal chemistry of the sulfate and nitrate-intercalated LDHs is expected to be quite different. Therefore the positions of the nitrate ions and their number in the present sample need to be determined. The nitrate content estimated by ion chromatography was found to be $0.75 \pm \pm 0.008$ per molecular formula unit. This is a close match with the layer charge predicted on the basis of the $[\mathrm{Al}] /[\mathrm{Zn}]$ ratio. It is gratifying that the $\mathrm{Zn}$ (AAS), $\mathrm{Al}$ (chemical gravimetry) and nitrate (ion chromatography) contents estimated by different techniques were mutually consistent, providing further support to the layer composition. The molecular formula resulting from this analysis is $\left[\mathrm{Zn}_{1.242} \mathrm{Al}_{3.672}(\mathrm{OH})_{12}\right]\left(\mathrm{NO}_{3}\right)_{1.5} \cdot x \mathrm{H}_{2} \mathrm{O}$. To determine the intercalated water, thermogravimetric analysis (TGA) was performed. The TGA curve (SI. 3) exhibits a two-step mass loss characteristic of a layered material with volatile interlayer ions. The first step $\left(<150^{\circ} \mathrm{C}\right)$ corresponds to loss of adsorbed water. The second step $\left(>150{ }^{\circ} \mathrm{C}\right.$ ) corresponds to loss of intercalated water followed closely by deanation and dehydroxylation of the layers. The observed total mass loss $(48.3 \%)$ is consistent with $y=2.25$. The following reaction fits the total mass loss:

$\left[\mathrm{Zn}_{0.621} \mathrm{Al}_{1.836}(\mathrm{OH})_{6}\right]\left(\mathrm{NO}_{3}\right)_{0.75} \cdot 2.25 \mathrm{H}_{2} \mathrm{O} \rightarrow 0.621 \cdot \mathrm{ZnO}+0.918 \cdot \mathrm{Al}_{2} \mathrm{O}_{3}$

Given a partial structure model, there are two possible approaches to determine the positions of the missing atoms. The more common approach is to use difference Fourier methods. In this instance, difference Fourier methods yielded uncertain positions for the interlayer atoms, specially as $\mathrm{N}$ and $\mathrm{O}$ have very similar electron densities. We therefore used an alternative approach that involves solving the structure in direct space using code FOX (Free Objects for Crystallography). This involves a global optimization algorithm with agreement between calculated and observed powder diffraction patterns as the cost function. In this approach, the nitrate ion is introduced into the interlayer in the manner of a molecule. The $\mathrm{N}-\mathrm{O}$ bond distance and $\mathrm{O}-\mathrm{N}-\mathrm{O}$ bond angle are held invariant as in a molecule and the nitrate ion is allowed to diffuse into the interlayer in random steps. At each step, the molecule is further rotated. An $\mathrm{O}$ atom is likewise introduced to account for the intercalated water molecule.

Once the positions of the interlayer atoms are found using FOX, these positions are incorporated into the structure model and refined using GSAS. The refinement gave an acceptable fit of the observed pattern (Fig. 1). The refinement conditions, atomic position parameters, bond lengths and bond angles are given in Tables 2-4.

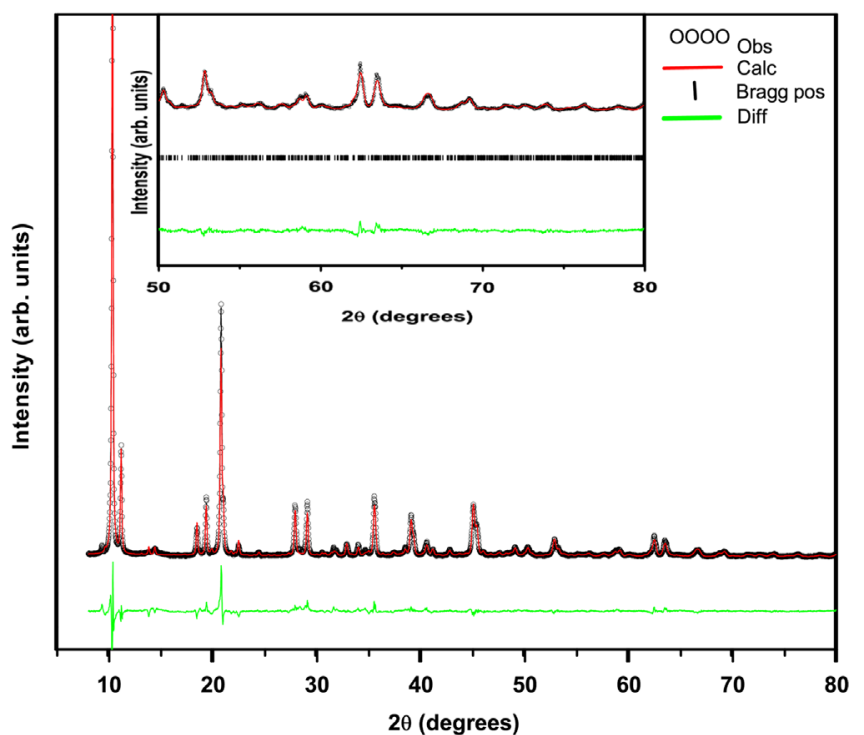

Fig. 1. Rietveld fit of the PXRD pattern of the [Zn-Al4-nitrate] LDH. (Inset: region between $50^{\circ}$ and $80^{\circ} 2 \theta$ is shown zoomed in.)

Table 2

Crystal data and structure refinement parameters of the [Zn-Al4-nitrate] LDH.

\begin{tabular}{ll}
\hline Crystal system & Monoclinic \\
\hline Space group & $\mathrm{P} 2 / n$ \\
Cell parameters $(\AA)$ & $a=10.2956(7), b=8.9221(6)$, \\
& $c=17.1605(5), \beta=95.210(5)$ \\
Volume $\left(\AA^{3}\right)$ & $1569.83(10)$ \\
Data points & 3639 \\
Parameters refined & 86 \\
No. of restraints & 31 \\
$R_{\mathrm{wp}}$ & 0.127 \\
$R_{\mathrm{p}}$ & 0.0999 \\
Reduced $\chi^{2}$ & 7.867 \\
$R(\mathrm{~F} 2)$ & 0.102 \\
$R_{\exp }$ & 0.045 \\
\hline
\end{tabular}

The refined structure viewed along the $a$ and $c$-axes are shown in Figs. 2 and 3. We make the following observations.

(i) The structure of the metal hydroxide layer is generated very well with $\mathrm{Al}-\mathrm{O}$ bond lengths close to those found in the bayerite precursor. The layers are staggered with respect to each other.

(ii) The nitrate ions are packed in the interlayer with their molecular planes inclined to the metal hydroxide layer. The three $\mathrm{N}-\mathrm{O}$ bonds have different lengths, varying by as much as $4 \%$. Two of the bonds are short varying by less than $0.01 \AA$ and one is long. The $\mathrm{O}$ atoms associated with the short bond are referred as "basal" oxygens and the atom associated with the long bond is referred as the "apical" oxygen. The apical oxygen atom always points towards the hydroxyl ions of the voids while the basal oxygen atoms of the nitrate ions point towards the hydroxyl ions coordinated to $\mathrm{Zn}^{2+}$ or $\mathrm{Al}^{3+}$ ions. The distance between the oxygen atoms of the nitrate ions and that of the hydroxyl groups of the layer correspond to hydrogen bonding distances (2.8-3.1 Å) (Fig. 3).

\subsection{Structure of [Zn-Al4-chromate] LDH}

The nitrate ion in the [Zn-Al4-nitrate] LDH is labile and could be quantitatively substituted by $\mathrm{CrO}_{4}^{2-}$ ions from solution to yield a [Zn-Al4-chromate] LDH having the approximate composition 
Table 3

Refined unit cell and atomic parameters of the [Zn-Al4-nitrate] LDH.

\begin{tabular}{|c|c|c|c|c|c|c|}
\hline $\begin{array}{l}\text { Atom } \\
\text { type }\end{array}$ & $\begin{array}{l}\text { Wyckoff } \\
\text { position }\end{array}$ & $\boldsymbol{x}$ & $\boldsymbol{y}$ & $z$ & SOF & $\begin{array}{l}\mathbf{U}_{\text {iso }} \\
\left(\AA^{\mathbf{2}}\right)\end{array}$ \\
\hline $\mathrm{Zn}$ & $4 \mathrm{e}$ & $0.7436(15)$ & $0.5008(12)$ & $0.5035(8)$ & 1.0 & 0.0099 \\
\hline Al1 & $4 \mathrm{e}$ & $0.0231(26)$ & $0.3127(34)$ & $0.5127(23)$ & 0.672 & 0.0127 \\
\hline $\mathrm{Al} 2$ & $4 \mathrm{e}$ & $0.4938(26)$ & $0.6623(27)$ & $0.4997(20)$ & 1.0 & 0.0284 \\
\hline $\mathrm{Al} 3$ & $4 \mathrm{e}$ & $0.2457(24)$ & $0.1702(22)$ & $0.4924(15)$ & 1.0 & 0.0212 \\
\hline Al4 & $4 \mathrm{e}$ & $0.2475(26)$ & $0.8452(24)$ & $0.4939(19)$ & 1.0 & 0.0086 \\
\hline 01 & $4 \mathrm{e}$ & $0.5773(26)$ & $0.506(4)$ & $0.5633(17)$ & 1.0 & 0.0971 \\
\hline $\mathrm{O} 2$ & $4 \mathrm{e}$ & $0.9295(27)$ & $0.4824(29)$ & $0.4664(26)$ & 1.0 & 0.1267 \\
\hline $\mathrm{O} 3$ & $4 \mathrm{e}$ & $0.6565(28)$ & $0.3160(24)$ & $0.4458(16)$ & 1.0 & 0.0473 \\
\hline $\mathrm{O} 4$ & $4 \mathrm{e}$ & $0.8536(28)$ & $0.3227(26)$ & $0.5529(18)$ & 1.0 & 0.0851 \\
\hline $\mathrm{O} 5$ & $4 \mathrm{e}$ & $0.1238(29)$ & $0.161(4)$ & $0.5729(17)$ & 1.0 & 0.0126 \\
\hline O6 & $4 \mathrm{e}$ & $0.1589(27)$ & $0.0054(31)$ & $0.4433(19)$ & 1.0 & 0.0127 \\
\hline 07 & $4 \mathrm{e}$ & $0.6519(24)$ & $0.6824(22)$ & $0.4442(15)$ & 1.0 & 0.0018 \\
\hline 08 & $4 \mathrm{e}$ & $0.8512(29)$ & $0.6686(23)$ & $0.5659(14)$ & 1.0 & 0.0075 \\
\hline 09 & $4 \mathrm{e}$ & $0.9022(28)$ & $0.190(4)$ & $0.4494(20)$ & 1.0 & 0.0127 \\
\hline 010 & $4 \mathrm{e}$ & $0.5843(27)$ & $0.829(4)$ & $0.5483(21)$ & 1.0 & 0.0126 \\
\hline 011 & $4 \mathrm{e}$ & $0.3961(31)$ & $0.806(4)$ & $0.4356(19)$ & 1.0 & 0.0126 \\
\hline 012 & $4 \mathrm{e}$ & $0.2954(30)$ & $0.0068(32)$ & $0.5580(17)$ & 1.0 & 0.0126 \\
\hline $\mathrm{N} 1$ & $4 \mathrm{e}$ & $0.5013(22)$ & $0.4316(25)$ & $0.2548(14)$ & 0.785 & 0.0127 \\
\hline $0-21$ & $4 \mathrm{e}$ & $0.5978(28)$ & $0.348(4)$ & $0.2777(19)$ & 1.0 & 0.0079 \\
\hline $0-22$ & $4 \mathrm{e}$ & $0.5096(30)$ & $0.514(4)$ & $0.1978(16)$ & 1.0 & 0.0127 \\
\hline $0-23$ & $4 \mathrm{e}$ & $0.3946(26)$ & $0.4188(35)$ & $0.2824(19)$ & 1.0 & 0.0098 \\
\hline N2 & $4 \mathrm{e}$ & $-0.0304(21)$ & $0.4710(25)$ & $0.7468(12)$ & 0.745 & 0.0127 \\
\hline $\mathrm{O}-24$ & $4 \mathrm{e}$ & $-0.0320(4)$ & $0.5385(34)$ & $0.8098(16)$ & 1.0 & 0.0157 \\
\hline $0-25$ & $4 \mathrm{e}$ & $-0.1199(32)$ & $0.377(4)$ & $0.7245(20)$ & 1.0 & 0.0422 \\
\hline $0-26$ & $4 \mathrm{e}$ & $0.0648(25)$ & $0.484(4)$ & $0.7084(17)$ & 1.0 & 0.0126 \\
\hline 013 & $4 \mathrm{e}$ & $0.8456(34)$ & $0.236(4)$ & $0.2145(21)$ & 1.0 & 0.0127 \\
\hline $\mathrm{Zn} 2$ & $4 \mathrm{e}$ & $-0.014(4)$ & $0.324(4)$ & $0.5194(23)$ & 0.242 & 0.0250 \\
\hline
\end{tabular}

$a=10.2956(7) \AA, b=8.9221(6) \AA, c=17.1605(5) \AA$, and $\beta=95.210(5)^{\circ}$.

Table 4

Bond distances and angles of the $\left[\mathrm{ZnAl} 4-\mathrm{NO}_{3}\right] \mathrm{LDH}$.

\begin{tabular}{lllr}
\hline Bond distances $(\AA)$ & & Bond angles in degrees \\
\hline Zn_O1 & $2.074(8)$ & N1_O-21 & $1.276(11)$ \\
Zn_O2 & $2.078(9)$ & N1_O-22 & $1.234(8)$ \\
Zn_O3 & $2.084(8)$ & N1_O-23 & $1.241(9)$ \\
Zn_O4 & $2.086(8)$ & & \\
Zn_O7 & $2.092(8)$ & O2_Zn2_O2 & $57.9(24)$ \\
Zn_O8 & $2.098(9)$ & O2_Zn2_O4 & $86.2(22)$ \\
& & O2_Zn2_O5 & $158.5(26)$ \\
Al1_O2 & $1.926(19)$ & O2_Zn2_O9 & $94.1(27)$ \\
Al1_O2 & $1.917(22)$ & O2_Zn2_O4 & $111.3(26)$ \\
Al1_O4 & $1.936(18)$ & O2_Zn2_O5 & $105.8(25)$ \\
Al1_O5 & $1.941(19)$ & & \\
Al1_O8 & $1.958(18)$ & O2_Al1_O2 & $55.7(31)$ \\
Al1_O9 & $1.918(19)$ & O2_Al1_O4 & $71.2(14)$ \\
& & O2_Al1_O5 & $171.3(33)$ \\
O13-O9 & $3.9895(1)$ & O2_Al1_O8 & $89.2(16)$ \\
O13-O3 & $4.6083(2)$ & O2_Al1_O9 & $89.6(24)$ \\
& & O-24_N2_O-25 & $120.83(27)$ \\
& & O-24_N2_O-26 & $119.71(27)$ \\
& & O-25_N2_O-26 & $119.13(30)$ \\
\hline
\end{tabular}

$\left[\mathrm{Zn}_{1.242} \mathrm{Al}_{3.672}(\mathrm{OH})_{12}\right]\left[\mathrm{CrO}_{4}\right]_{0.732} \cdot 7.74 \mathrm{H}_{2} \mathrm{O}$. The product was ordered as judged by the sharp Bragg reflections in the PXRD pattern suggesting that the exchange is topotactic. The pattern could be indexed to a monoclinic cell in the $P 2_{1} / n$ space group (see SI. 1 and 2). The structure was refined using a procedure similar to that described earlier by taking the metal hydroxide layer obtained from nickelalumite as a partial structure model. FOX indicates two $\mathrm{CrO}_{4}^{2-}$ ion positions in the unit cell. The $\mathrm{CrO}_{4}^{2-}$ ions orient themselves in such a way that one of their $C_{2}$ axes is parallel to the 2 axis of the monoclinic cell, thereby lowering the coordination symmetry to $D_{2 \mathrm{~d}}$ [12]. The subsequent Rietveld refinement yielded a reasonable fit of the observed pattern (Fig. 4).

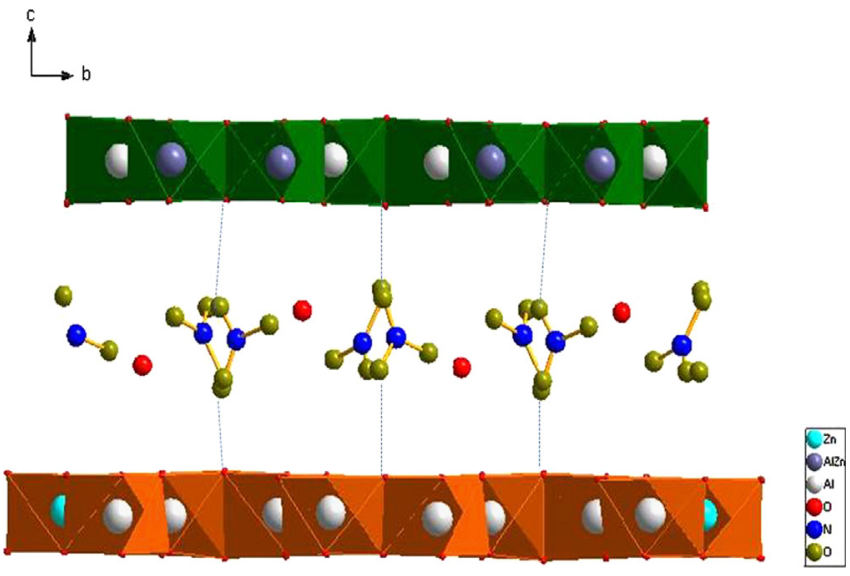

Fig. 2. The structure of the [Zn-Al4-nitrate] LDH viewed along the $a$-axis. Hydrogen bonding interactions are indicated with dotted lines.

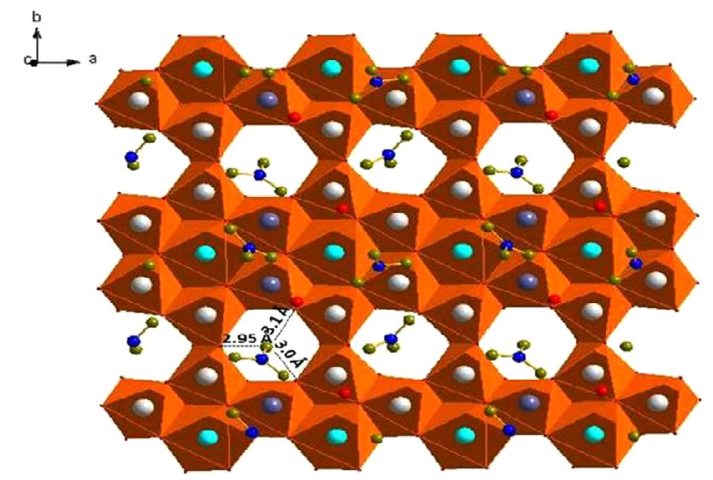

Fig. 3. The structure of the [ $\mathrm{Zn}-\mathrm{Al} 4-$ nitrate] LDH down the $c$-axis.

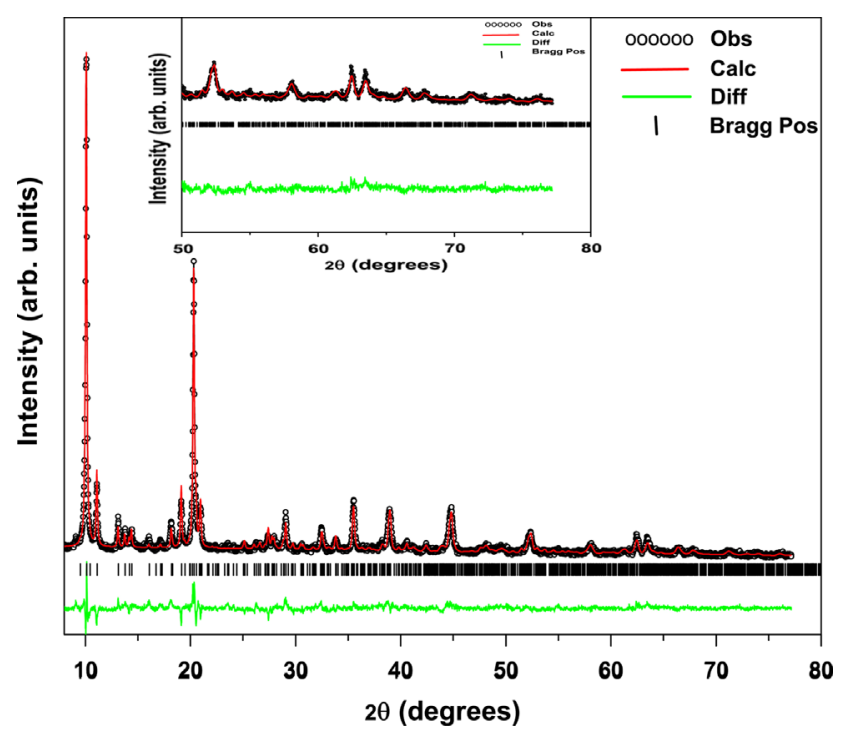

Fig. 4. Rietveld fit of the [Zn-Al4-chromate] LDH. (Inset: region between $50^{\circ}$ and $80^{\circ} 2 \theta$ is shown zoomed in.)

The refinement conditions, position parameters and bond lengths and bond angles are given in SI. 4-6. The [Zn-Al4-chromate] LDH is isostructural with mineral nickelalumite with the $\mathrm{CrO}_{4}^{2-}$ ions substituting for sulfate ions isomorphously. 


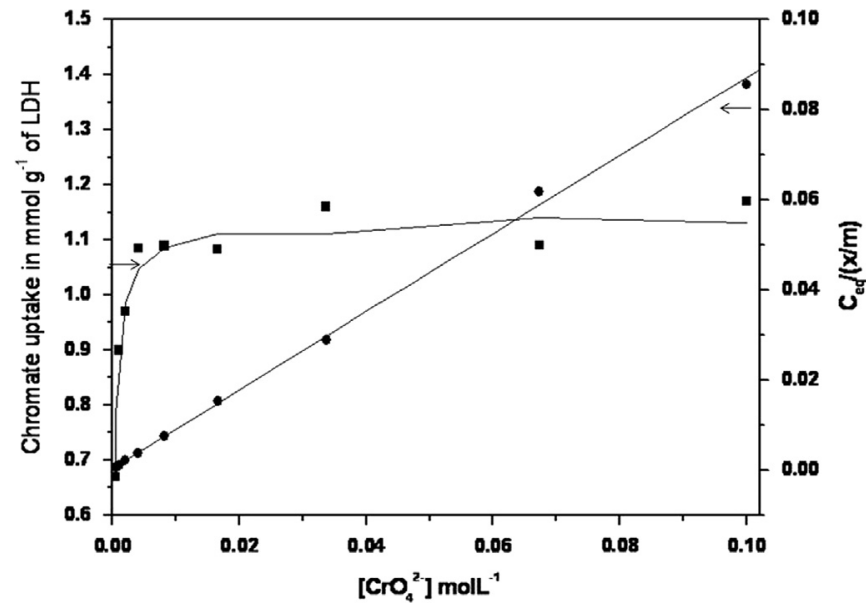

Fig. 5. Adsorption isotherm and Langmuir plot for chromate uptake by the [Zn-Al4-nitrate] LDH.

Table 5

Chromate uptake characteristics of the $\left[\mathrm{Zn}-\mathrm{Al} 4-\mathrm{NO}_{3}\right] \mathrm{LDH}$

\begin{tabular}{ll}
\hline $\begin{array}{l}\mathrm{K}_{2} \mathrm{CrO}_{4} \\
\left(\mathrm{~mol} \mathrm{~L}^{-1}\right)\end{array}$ & $\begin{array}{l}\text { Chromate uptake } \\
(\mathrm{mmol} \mathrm{g}\end{array}$ \\
\hline 0.00509 & $\mathrm{LDH})$ \\
0.00102 & 0.67 \\
0.00204 & 0.90 \\
0.00409 & 0.97 \\
0.00817 & 1.084 \\
0.0166 & 1.089 \\
0.0337 & 1.083 \\
0.0673 & 1.16 \\
0.1 & 1.09 \\
\hline
\end{tabular}

\subsection{Chromate uptake studies}

Given that the nickelalumite structure has a natural affinity for anions of tetrahedral molecular symmetry [11], the [Zn-Al4nitrate] LDH is a candidate material for green chemistry applications for efficient sorption of $\mathrm{CrO}_{4}^{2-}$ ions from waste water. UV-vis spectra of the chromate intercalated LDH exhibits bands corresponding to that of free chromate indicating intercalation of chromate has occurred (SI. 7). The anion exchange reaction yields a chromate carrying capacity of $1.28 \mathrm{mmol} \mathrm{g}^{-1}$ of LDH which is close to $95 \%$ of the stoichiometric requirement. A soaking time of $24 \mathrm{~h}$ was required to attain this capacity suggesting slow kinetics and high barrier to the exchange. Subsequent sorption experiments were therefore carried out for $24 \mathrm{~h}$. Fig. 5 shows the results of chromate uptake studies from chromate solutions of different concentrations. Unlike in the case of the brucite derived LDHs, where such studies have to be carried out in decarbonated water to avoid carbonate intercalation, here no such precautions needed to be taken and in no case was carbonate intercalation observed. The LDH was observed to take up chromate over the entire range of concentrations studied. At low initial concentrations of chromate, uptake was low and gradually increased with increasing concentration with uptake close to saturation value being observed at concentration as low as $\sim 0.004 \mathrm{M}$. The chromate uptake observed at different initial concentrations is given in Table 5. The uptake studies were carried out under equilibrium conditions in $1 \mathrm{M} \mathrm{KNO}_{3}$ solution which allows us to process the data within the limits of the Langmuir adsorption isotherm. The Langmuir plot of $\left[C_{\mathrm{eq}} /(x / m)\right]$ versus $C_{\mathrm{eq}}$ should define a straight line. Linear behavior is observed for the entire range of concentrations studied.

\section{Conclusions}

The [ $\mathrm{Zn}-\mathrm{Al} 4-\mathrm{A}]$ LDH crystallizes in monoclinic symmetry in which the metal hydroxide layers are stacked along the c-crystallographic axis, whereas the 2 axis of the crystal is parallel to the $b$-crystallographic axis. The stacking of metal hydroxide layers results in a distorted prismatic interlayer site, owing to the absence of 3-fold symmetry. The resulting symmetry can best be described as $D_{2 \mathrm{~d}}$, and the nitrate ions are included with their molecular plane tilted at an angle to the plane of the metal hydroxide slabs. The chromate ion however is incorporated with one of its 2-fold axes parallel to the $b$-axis of the crystal. This symmetry match enhances the affinity of the LDH for tetrahedral ions. While chromate itself is not labile, given its higher charge, the nitrate is labile and is replaced by chromate ions from solution making the nitrate LDH a good candidate compound for chromate sorption.

\section{Acknowledgments}

The authors thank the Department of Science and Technology (DST), Government of India (GOI) for financial support. S.B. is a Senior Research Fellow (NET) of the University Grants Commission, GOI. P.V.K. is a recipient of the Ramanna Fellowship of the DST, GOI. We thank Supreeth Nagendran for help with UV-vis measurements.

\section{Appendix A. Supporting information}

Supplementary data associated with this article can be found in the online version at http://dx.doi.org/10.1016/j.jssc.2014.02.031.

\section{References}

[1] R. Rothbauer, F. Zigan, H. O’Daniel, Z. Kristallogr. 125 (1967) 317.

[2] H.D. Megaw, Z. Kristallogr. 87 (1934) 185.

[3] H.J. Bosmans, Acta Crystallogr. B26 (1970) 649.

[4] V. Hanschild, Z. Anorg. Allg. Chem. 324 (1963) 15.

[5] C.J. Serna, J.L. Rendon, J.E. Iglesias, Clays Clay Miner. 30 (1982) 180.

[6] A.V. Besserguenev, A.M. Fogg, R.J. Francis, S.J. Price, D. O'Hare, V.P. Isupov, B.P. Tolochko, Chem. Mater. 9 (1997) 241.

[7] S. Britto, P.V. Kamath, Inorg. Chem. 48 (2009) 11646.

[8] M. Rajamathi, G.S. Thomas, P.V. Kamath, Proc. Indian Acad. Sci 113 (2001) 671.

[9] A.M. Fogg, G.R. Williams, R. Chester, D. O’Hare, J. Mater. Chem. 14 (2004) 2369.

[10] S. Britto, P.V. Kamath, Inorg. Chem. 49 (2010) 11370.

[11] Y. Uvarova, E. Sokolova, F.C. Hawthorne, V.V. Karpenko, A.A. Agakhanov, L.A. Pautov., Can. Mineral. 43 (2005) 1511.

[12] G.R. Williams, S.J. Moorhouse, T.J. Prior, A.M. Fogg, N.H. Rees, D. O’Hare, Dalton Trans. 40 (2011) 6012.

[13] S. Britto, P.V. Kamath, Inorg. Chem. 50 (2011) 5619.

[14] A.C. Larson, R.B. Von Dreele, General structure analysis system (GSAS), , 2004 (Los Alamos Laboratory report LAUR 86-748).

[15] V. Favre-Nicolin, R. Cerny, J. Appl. Crystallogr. 35 (2002) 734 (See also) http:// objcryst.sourceforge.net. 